\title{
Anti-c-Met Antibody-drug Conjugate TR1801
}

National Cancer Institute

\section{Source}

National Cancer Institute. Anti-c-Met Antibody-drug Conjugate TR1801. NCI Thesaurus. Code C158513.

An antibody-drug conjug ate (ADC) consisting of a non-agonizing anti-c-Met humanized monoclonal antibody that is linked in a site-specific manner to a pyrrolobenzodiazepine dimer (PBD) toxin, with potential antineoplastic activity. Upon administration, the monoclonal antibody moiety targets and binds to the c-Met protein, which is overexpressed in certain tumor types. Upon antibody/antigen binding and internalization, the imine groups of the PBD moiety bind to the N2 positions of guanines on opposite strands of tumor cell DNA. This induces interstrand cross-links in the minor groove of DNA and inhibits DNA replication, which inhibits the proliferation of c-Met-expressing cells. c-Met, also known as hepatocyte growth factor receptor (HGFR), is a receptor tyrosine kinase that is overexpressed or mutated in many tumor cell types and plays a key role in tumor cell proliferation, survival, invasion, metastasis, and tumor angiogenesis. 